\title{
Comunicação
}

[Communication]

\section{Avaliação laboratorial de compostos fibrosos em alimentos e fezes bovinas sob diferentes ambientes físicos}

[Laboratorial evaluation of fibrous compounds in feeds and cattle feces under different physical environments]

\author{
D.I. Gomes ${ }^{1}$, E. Detmann ${ }^{2,4 *}$, T.N.P. Valente ${ }^{3}$, S.C. Valadares Filho ${ }^{2,4}$, A.C. Queiroz ${ }^{2,4}$ \\ ${ }^{1}$ Aluna de pós-graduação - Zootecnia - UFV - Viçosa, MG \\ ${ }^{2}$ Universidade Federal de Viçosa \\ Av. PH Rolfs, $\mathrm{s} / \mathrm{n}$ \\ 36570-000- Viçosa, MG \\ ${ }^{3}$ Universidade Estadual do Norte Fluminense - Campos dos Goytacazes, RJ \\ ${ }^{4}$ Bolsista de Produtividade - CNPq e Pesquisador do INCT-Ciência Animal
}

A partir do surgimento do sistema Ankom ${ }^{\circledR}$ para análises de fibras, novas perspectivas foram dadas ao uso de tecidos (sacos filtrantes) na avaliação de alimentos, incorporando-os em análises laboratoriais voltadas à estimação do teor de componentes fibrosos insolúveis, como a fibra em detergente neutro (FDN) e a fibra em detergente ácido (FDA). Este sistema tem se mostrado vantajoso por ter menor custo, ser menos laborioso (Cherney, 2000) e não apresentar diferenças em comparação ao sistema convencional com o uso de vidrarias (Vogel et al., 1999).

No entanto, diferentes equipamentos encontramse disponíveis para realização de análises de componentes fibrosos, os quais são diferenciados, principalmente, no tocante ao ambiente físico para condução dos procedimentos de extração, sendo estes pressurizados ou não pressurizados. Considerando-se uma situação hipotética na qual são mantidas fixas as condições de amostra, recipiente (saco filtrante) e de reagentes químicos, alterações no ambiente físico podem influenciar a eficiência de extração dos compostos não fibrosos. Contudo, não foram encontradas referências na literatura consultada a respeito da influência de tal variação sobre os teores de compostos fibrosos insolúveis em alimentos e fezes bovinas.

Assim, definiu-se como objetivo avaliar os teores de FDN e FDA em alimentos volumosos e concentrados e em fezes bovinas, utilizando-se sacos filtrantes sob dois diferentes ambientes físicos de extração: pressurizado e não pressurizado.

O experimento foi realizado no Laboratório de Nutrição Animal do Departamento de Zootecnia da Universidade Federal de Viçosa, Viçosa, MG. Para a feitura das análises, foram utilizados sacos F57 (Ankom ${ }^{\circledR}$ ) e extratores de fibra Ankom ${ }^{220}{ }^{\circledR}$, com ambiente pressurizado, e Tecnal TE-149®, com ambiente não pressurizado. Foram utilizadas 20 amostras de alimentos concentrados, 20 amostras de volumosos e 20 amostras de fezes bovinas. O banco de amostras foi construído buscando-se obter material com alta diversidade, de forma a conseguir a maior amplitude possível de teores de FDN e FDA.

As amostras de forragens úmidas e fezes foram secas sob ventilação forçada $\left(60^{\circ} \mathrm{C}\right)$ e, em conjunto com as demais amostras, processadas em moinho de facas com peneiras de porosidade $1 \mathrm{~mm}$ (Valente, 2010) e quantificadas quanto ao

Recebido em 19 de maio de 2010

Aceito em 14 de fevereiro de 2011

*Autor para correspondência (corresponding author)

E-mail:detmann@ufv.br).

Trabalho financiado pelo CNPq, pelo INCT-Ciência Animal e pela FAPEMIG 
teor de matéria seca (MS), utilizando estufa não ventilada $\left(105^{\circ} \mathrm{C} / 16\right.$ horas $)$. Posteriormente, as amostras foram acondicionadas em duplicatas nos sacos, seguindo a proporção de $20 \mathrm{mg}$ $\mathrm{MS} / \mathrm{cm}^{2}$ de superfície, perfazendo o total de 120 sacos, os quais foram selados por calor.

Para avaliação dos teores de FDN, produziu-se detergente neutro segundo recomendações de Mertens (2002), omitindo-se o uso de sulfito de sódio e utilizando-se $\alpha$-amilase termoestável (Termamyl 2X, Novozymes). Para os procedimentos de extração, a relação detergente neutro:amostra foi mantida em $100 \mathrm{~mL} / \mathrm{g}$ de MS, com tempo efetivo de extração de uma hora, em temperatura de $100^{\circ} \mathrm{C}$. Um saco de cada amostra foi analisado em cada um dos equipamentos que representam os diferentes ambientes de extração. Após a extração, foram realizadas lavagens sequenciais com água quente e acetona. Após esse tratamento, os sacos foram secos em estufa com ventilação forçada $\left(60^{\circ} \mathrm{C} / 72\right.$ horas $)$ e, sequencialmente, em estufa não ventilada ( $105^{\circ} \mathrm{C} / 45$ minutos), acondicionados em dessecador e pesados.

A avaliação dos teores de FDA foi realizada sequencialmente às avaliações de FDN, utilizando-se os mesmos procedimentos de extração e pesagem. O detergente ácido foi produzido segundo recomendações de Van Soest e Robertson (1985).
Nenhum procedimento para correção quanto aos compostos nitrogenados e cinzas insolúveis em detergente neutro ou ácido foi realizado. Previamente aos procedimentos de extração, os sacos foram lavados com detergente neutro em ebulição, água quente e acetona e secos e pesados conforme o procedimento descrito anteriormente para se obterem as taras.

As comparações entre os teores de FDN e FDA obtidos nos diferentes ambientes de extração foram realizadas por intermédio de ajustamento de equação de regressão linear simples dos valores obtidos em ambiente pressurizado (Y) sobre os valores obtidos em ambiente não pressurizado $(\mathrm{X})$, sendo a avaliação estatística conduzida sob as seguintes hipóteses: $\mathrm{H}_{0}: \beta_{0}=0$, e $\beta_{1}=1$; vs. $H_{a}$ : não $H_{0}$. Para o caso de não aceitação da hipótese de nulidade, concluiu-se serem os ambientes de extração diferentes. Os procedimentos estatísticos foram realizados por intermédio do PROC REG implementado no programa SAS (Littel et al., 1991).

Os teores de FDN e FDA obtidos em ambiente não pressurizado foram, em média, mais altos em 5,16 e 5,$41 ; 2,18$ e 4,37 ; e 9,20 e 8,05 pontos percentuais, considerando-se concentrado, fezes e volumoso, respectivamente. Para todo o material avaliado, foram observadas diferenças entre ambientes de extração $(\mathrm{P}<0,01)$ (Tab. 1), corroborando as maiores estimativas de FDN e FDA obtidas em ambiente não pressurizado (Fig. 1).

Tabela 1. Estimativas de parâmetros da regressão linear entre os teores de fibra em detergente neutro e fibra em detergente ácido, com percentual da matéria seca, obtidos em ambiente não pressurizado (X) e pressurizado (Y)

\begin{tabular}{|c|c|c|c|c|c|}
\hline \multirow[b]{2}{*}{ Material } & \multicolumn{2}{|c|}{ Estimativa de parâmetro } & \multirow[b]{2}{*}{$\mathrm{r}^{2}$} & \multirow[b]{2}{*}{$\mathrm{S}_{\mathrm{xy}}$} & \multirow[b]{2}{*}{ Valor- $\mathrm{P}^{3}$} \\
\hline & Intercepto & Coef. de inclinação & & & \\
\hline & \multicolumn{5}{|c|}{ Fibra em detergente neutro } \\
\hline Concentrado $^{1}$ & $-3,0537$ & 0,9568 & 0,9729 & 2,20 & $<0,0001$ \\
\hline Volumoso $^{1}$ & 3,8171 & 0,8353 & 0,3802 & 6,75 & $<0,0001$ \\
\hline Fezes $^{1}$ & $-13,4914$ & 1,1500 & 0,8340 & 2,37 & $<0,0001$ \\
\hline \multirow[t]{2}{*}{ Geral $^{2}$} & $-2,6174$ & 0,9573 & 0,9031 & 5,10 & $<0,0001$ \\
\hline & \multicolumn{5}{|c|}{ Fibra em detergente ácido } \\
\hline Concentrado $^{1}$ & $-0,1371$ & 0,8242 & 0,8952 & 3,40 & $<0,0001$ \\
\hline Volumoso $^{1}$ & 8,9302 & 0,6486 & 0,4986 & 4,60 & $<0,0001$ \\
\hline Fezes $^{1}$ & $-1,7390$ & 0,9490 & 0,7137 & 5,05 & 0,0041 \\
\hline Geral $^{2}$ & $-1,9829$ & 0,9085 & 0,8666 & 4,73 & $<0,0001$ \\
\hline
\end{tabular}

${ }^{1} \mathrm{n}=20 .^{2} \mathrm{n}=60 .{ }^{3}$ Nível descritivo de probabilidade para o erro tipo I associado a $\mathrm{H}_{0}: \beta_{0}=0$ e $\beta_{1}=1$. 


\section{Gomes et al.}
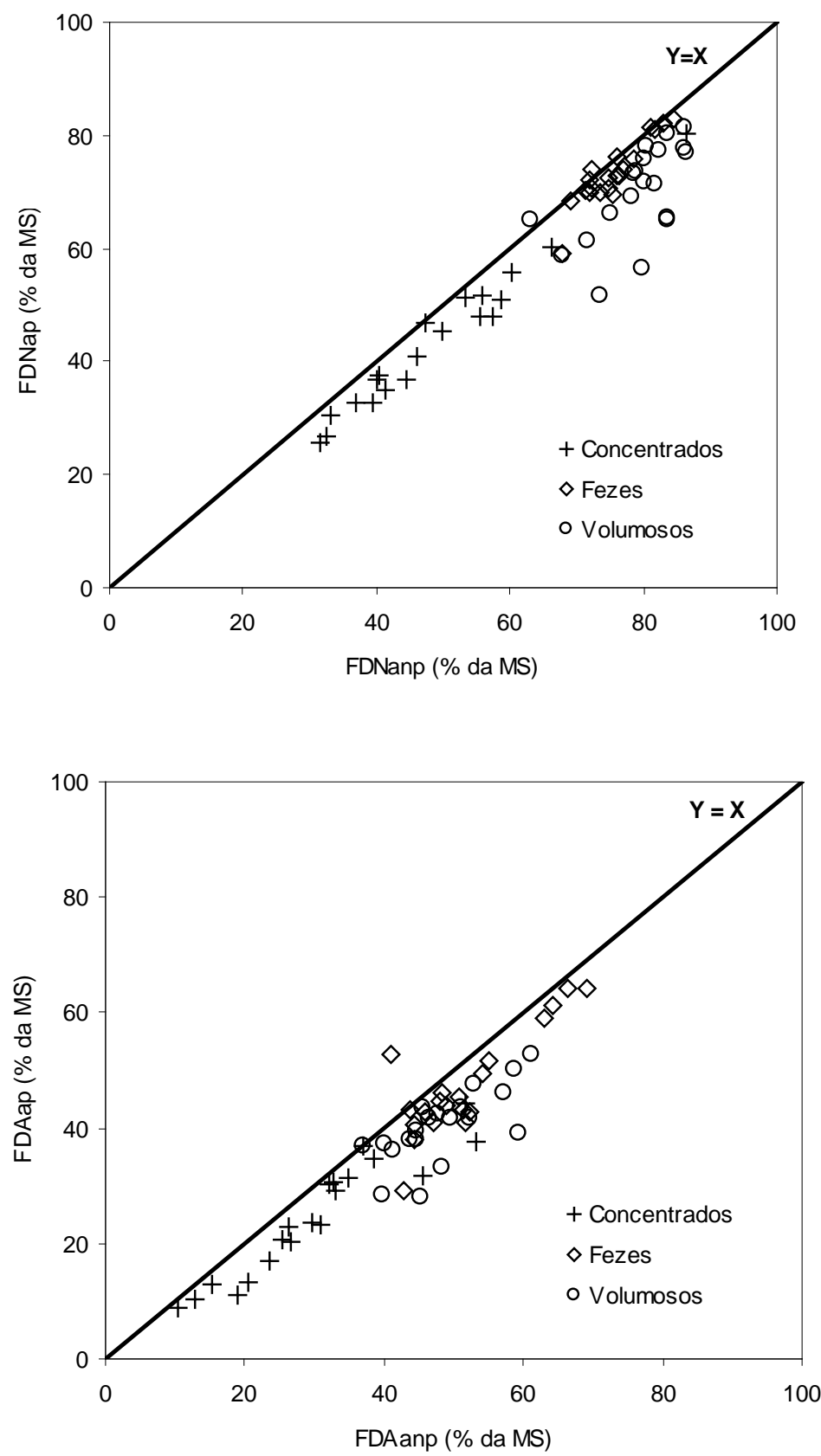

Figura 1. Relação entre os teores de fibra em detergente neutro (FDN) e fibra em detergente ácido (FDA), obtidos em ambientes pressurizado (ap) e não pressurizado (anp).

A principal diferença física entre os ambientes pressurizado e não pressurizado reside sob a forma como o detergente interage com a amostra. No ambiente pressurizado, com o início do processo de aquecimento, ocorre aumento da pressão atmosférica sobre a solução de detergente, o que eleva seu ponto de ebulição.
Assim, na temperatura de extração utilizada $\left(100^{\circ} \mathrm{C}\right)$, não há ebulição da solução. Em ambientes não pressurizados, não há acúmulo de pressão, observando-se, portanto, ebulição da solução, a qual é mantida no sistema com o auxílio de um condensador. 
Sacos filtrantes, como o F57(Ankom $\left.{ }^{\circledR}\right)$, são confeccionados em esquema que não envolve tecelagem, com a união de fibras sem arranjo geométrico definido. Isto confere a este tipo de tecido menor porosidade em relação aos tecidos produzidos por tecelagem, o que se mostra favorável no tocante à prevenção da perda de partículas fibrosas durante o processo de análise (Casali et al., 2009; Valente, 2010).

Baixas porosidades, contudo, dificultam a eliminação de gases do interior dos sacos, como verificado em estudos de degradação in situ (Udén et al., 1974). Por analogia, considerandose a formação de bolhas de gás (vapor) durante a extração em ambiente não pressurizado, haveria retenção destas quando formadas no interior dos sacos. Isto poderia comprometer diretamente o contato do detergente com as amostras, reduzindo a eficiência de extração dos materiais a serem solubilizados e implicando, consequentemente, maiores estimativas de concentração de componentes fibrosos, como observado neste trabalho (Fig. 1).

A exatidão dos teores de compostos fibrosos com o uso de ambientes pressurizados utilizando-se sacos como recipientes foi verificada em alguns trabalhos (Vogel et al., 1999; Casali et al., 2009; Valente, 2010). Desta forma, diante dos resultados obtidos neste estudo, o uso de ambientes não pressurizados mostra-se incompatível com a avaliação dos teores de compostos fibrosos em alimentos e fezes bovinas utilizando-se sacos filtrantes.

Palavras-chave: F57, fibra em detergente ácido, fibra em detergente neutro, saco filtrante

\begin{abstract}
The neutral detergent fiber (NDF) and acid detergent fiber (ADF) contents were evaluated in concentrates, forages, and cattle feces using filter bags under pressured or non-pressured physical environments. Twenty samples of each material were used. The contents obtained under different environments were compared by linear regression. The NDF and ADF estimates were found different between physical environments for all materials $(P<0.01)$. The utilization of pressured environment is recommended to avoid gas accumulation in the bags, which may compromise the detergent action.
\end{abstract}

Keywords: F57, acid detergent fiber, neutral detergent fiber, filter bags

\section{REFERÊNCIAS BIBLIOGRÁFICAS}

CASALI, A.O.; DETMANN, E.; VALADARES FILHO, S.C. et al. Estimação de teores de componentes fibrosos em alimentos para ruminantes em sacos de diferentes tecidos. Rev. Bras. Zootec., v.38, p.130-138, 2009.

CHERNEY, D.J.R. Characterization of forages by chemical analysis. In: GIVENS, D.I.; OWEN, E.; AXFORD, R.F.E. et al. (Eds). Forage evaluation in ruminant nutrition. Wallingford: CAB International, 2000. p.281-300.

LITTELL, R.C.; FREUND, R.J.; SPECTOR, P.C. SAS system for linear models. Cary: SAS Institute, 1991. 329p.

MERTENS, D.R. Gravimetric determination of amylase treated neutral detergent fiber in feeds with refluxing in beaker or crucibles: collaborative study. J. AOAC Int., v.85, p.12171240, 2002.
UDÉN, P.; PARRA, R.; VAN SOEST, P.J. Factors influencing reliability of the nylon bag technique. J. Dairy Sci., v.57, p.622-622, 1974.

VALENTE, T.N.P. Utilização de tecidos na avaliação de compostos fibrosos e na degradação ruminal in situ de alimentos para ruminantes. 2010. 90f. Tese (Doutorado) Universidade Federal de Viçosa, Viçosa, MG.

VAN SOEST, P.J.; ROBERTSON, J.B. Analysis of forage and fibrous foods. Ithaca: Cornell University, 1985. 202p.

VOGEL, K.P.; PETERSEN, J.F.; MASTERSON, S.D. et al. Evaluation of a filter bag system for NDF, ADF, and IVDMD forage analysis. Crop Sci., v.39, p.276-279, 1999. 